Revista de Filosofía

ISSN: 0034-8244

http://dx.doi.org/10.5209/resf.72290

\title{
Sujeto y tolerancia. A propósito de Lessing y el Nathan
}

\author{
Oscar Parcero Oubiña ${ }^{1}$
}

Recibido: 11 de enero de 2018 / Aceptado: 25 de abril de 2019

Resumen: Este trabajo se centra en la relación entre la tolerancia y su subyacente concepción de la subjetividad. Se intentará mostrar cómo cabe hablar de dos concepciones de la tolerancia, "pasiva" y "activa", derivadas de dos concepciones de la subjetividad en las que el encuentro con el otro se integra de maneras antitéticas. La obra de Lessing servirá para ilustrar una concepción del sujeto y, con éste, de la tolerancia, alternativa a la hegemónica concepción ilustrada de otros autores.

Palabras clave: Nathan el sabio; tolerancia; sujeto; Lessing; Ilustración.

\section{[en] Subject and Tolerance. Regarding Lessing's Nathan}

Abstract: This paper focuses on the relationship between tolerance and the underlying conception of subjectivity. It will try to argue that two conceptions of tolerance can be considered, "passive" and "active", both derived from two conceptions of subjectivity in which the meeting with the other integrates antithetically. The work of Lessing will serve to illustrate a conception of subjectivity and, along with it, of tolerance, which is alternative to the hegemonic conception of other Enlightenment authors.

Keywords: Nathan the Wise; tolerance; subject; Lessing; Enlightenment.

Sumario: 1 . Tolerancia pasiva, o la primacía del yo individual; 2 . Tolerancia activa, o la búsqueda del yo ante el otro; 3 . Referencias bibliográficas.

Cómo citar: Parcero Oubiña, O. (2020): "Sujeto y tolerancia. A propósito de Lessing y el Nathan", en Revista de Filosofía 45 (2), 267-283.

1 Departamento de Filosofía e Antropoloxía Universidade de Santiago de Compostela oscar.parcero@usc.es 
Les autres forment l'homme; je le récite et en représente un particulier bien mal formé, et lequel, si j'avais à façonner de nouveau, je ferais vraiment bien autre qu'il n'est.

Méshui, c'est fait.

Michel de Montaigne, «Du repentir» (Essais, III, 2)

Reconocida como uno de los principios constitutivos del ideal moderno-ilustrado de una sociedad madura, la tolerancia destaca por ser, más particularmente, piedra de toque de una intersubjetividad operada desde los principios de libertad y autonomía que constituyen en primera instancia al sujeto. No sorprende, pues, que la tolerancia esté muy presente en escritos de muy diversos autores que, grosso modo, entre los siglos XVI y XVIII, reivindican o celebran, dependiendo del caso, una sociedad conformada por sujetos maduros capaces de tolerar aquello que en realidad desaprueban o, incluso, íntimamente desprecian; sujetos, en fin, capaces de autorregularse de manera civilizada, sin necesidad de recurrir a la violencia y a la confrontación en tanto que aquello que la provocaría es neutralizado por la práctica de la tolerancia. Esta capacidad de armonizar encuentros y desencuentros entre sujetos de una comunidad supondría una de las más altas conquistas del proyecto ilustrado, y estaría en la base del más alto ideal de una "paz perpetua", como resultado de una política de la subjetividad que no puede ser entendida sin el ejercicio de la tolerancia (y, sobre todo, vicecersa).

En las páginas que siguen se intentará contraponer dos grandes concepciones de la tolerancia que encontramos en el contexto de la Ilustración en que este concepto más plenamente se consolida, a pesar de que sea sólo una de ellas la que hegemónicamente se imponga. La diferencia entre ambas, que implican prácticas casi antitéticas, vendría dada por sendas concepciones contrapuestas de la subjetividad. Intentaremos mostrarlo centrándonos en la paradigmática figura de Gotthold Ephraim Lessing, a quien podremos reivindicar como representante de una concepción de la subjetividad y, con ella, de la tolerancia, contrapuesta a la dominante en la propia Ilustración que él mismo abandera.

\section{Tolerancia pasiva, o la primacía del yo individual}

Una de las más conocidas formulaciones del principio ilustrado de tolerancia, que escuchamos repetida con frecuencia -y bastante ligereza- cuando se quiere señalar qué caracteriza a las sociedades libres y democráticas, por contraposición a las tiránicas y represivas, es aquélla atribuida a Voltaire que afirma que «no estoy de acuerdo con lo que usted dice, pero defenderé hasta la muerte su derecho a decirlo» ${ }^{2}$. Esta sencilla frase puede servirnos de introducción, por cuanto en ella identificamos

2 La frase no es de Voltaire; la atribución es errónea, como tanto sucede con este tipo de sentencias que conforman el repertorio de citas colectivo. Su autora es la biógrafa de Voltaire Evelyn Beatrice Hall, y se encuentra en su obra de 1906 The Friends of Voltaire (cf. Boller y George 1989, pp. 124-125). 
dos rasgos característicos del ejercicio de la tolerancia: el primero, su necesario valor absoluto; el segundo, su vinculación con el ámbito del discurso.

La tolerancia adquiere necesariamente valor absoluto en la medida en que por ello funciona, justamente, como aniquiladora de las excluyentes pretensiones absolutas de cualquier otro principio particular ${ }^{3}$. Yo podré tener mi criterio, mas éste nunca podrá anular el del prójimo, ya que existe un criterio que está por encima de cualquier otro - de valor absoluto, en virtud de su valor intersubjetivo-, a saber, que cada uno tiene derecho a tener su propio criterio, y con él, a expresar su propia opinión. Y hablamos de criterio y opinión porque, en segundo lugar, la supuesta máxima de Voltaire -que aunque no haya dicho, suponemos que subscribiría con gusto- nos remite al ámbito del discurso; nada se nos dice de que cada uno pueda hacer lo que le parezca, pues es evidente que ciertas acciones conflicten abiertamente con el prójimo ${ }^{4}$. Para expresarlo de la manera más sencilla, diremos que no se puede tolerar al intolerante.

Como un corolario ya no tan obvio de esta obviedad podemos entender la noción de "tolerancia represiva" que, ya en el siglo XX, y desde una revisión crítica del proyecto ilustrado, elaborará Marcuse. Marcuse denuncia que «la realización del objetivo de la tolerancia exige intolerancia hacia orientaciones políticas, actitudes y opiniones dominantes, y, en cambio, la extensión de la tolerancia a orientaciones políticas, actitudes y opiniones fuera de la ley o eliminadas ${ }^{5}$. Si no se puede tolerar todo, pues hay cosas que son intolerables, y ya no sólo el intolerante es intolerable, ¿dónde trazamos la sutil línea que separa lo tolerable de lo intolerable? Para Marcuse está claro: será la que delimite los dominios de las fuerzas hegemónicas. Si algún poder heterodoxo está dentro de esos dominios y puede rivalizar con los principios fundamentales y eventualmente amenazarlos, no puede ser tolerado, pues pone en riesgo el statu quo dentro del cual tiene cabida el ejercicio de la tolerancia reconocido como legítimo. Toda comunidad se dota de sus principios, que regulan la inclusión de quienes los obedecen y la exclusión de quienes no lo hacen $\mathrm{y}$, muy particularmente, de quienes de una u outra manera los ponen en riesgo. En consecuencia, (sólo) será tolerable aquella discordancia que, estando ya neutralizada, no suponga una amenaza para los principios hegemónicos de una comunidad (es decir, una heterodoxia impotente), siendo intolerable toda otra que evidencie un potencial rivalizador de hegemonía alternativa. $\mathrm{O}$ dicho de una manera más simple: es tolerable la discordancia, no lo es la discordia ${ }^{6}$.

Hablamos de "fuerzas hegemónicas", pues la expresión parece ajustarse mejor a la lectura de Marcuse. Ahora bien, si tuviésemos que expresar la misma idea con

3 Formalmente paradójica, la tolerancia opera de manera análoga a la tan célebre consigna del 68 que prohibía prohibir. Lejos de desligitimarla, la paradoja que subyace a la tolerancia la refuerza, poniendo de manifiesto cómo ningún principio particular puede, efectivamente, arrogarse carácter absoluto.

4 Propiamente no constituye una excepción la censura de determinadas afirmaciones, fundamentada sobre la convicción de que éstas no se circunscriban al mero ámbito del discurso y sean, en realidad, acciones ofensivas en sí mismas, palabras que ejercen violencia; de ahí las distintas fórmulas jurídicas desarrolladas en esta línea, como pueda ser la del "derecho al honor", reconocido, por ejemplo, en la constitución española como un "derecho fundamental" (art. 18). En el fondo, el problema radica en los supuestos límites entre el decir y el hacer, en última instancia inexistentes. Aunque no entraremos propiamente en esta cuestión, tendremos oportunidad de apuntarla al hilo de nuestro discurso.

5 Marcuse (1965), p. 95.

6 Quizás demasiado simple, la expresión puede, no obstante, valer. Pues “discordancia” nos remite a diversidad, mientras que "discordia" nos habla ya más bien de oposición. El uso habitual de ambos términos, por otro lado, recoge bien la distinción que, en última instancia, pone de relieve la crítica de Marcuse. 
una fórmula más afín al contexto cultural y filosófico de la Modernidad ilustrada en la que se consolida el ideal de tolerancia, ésta sería la de "voluntad general" o la de "bien común". De cómo se relaciona esta noción con el ideal de la tolerancia da buena cuenta uno de los más conocidos fragmentos de la obra de Rousseau Del contrato social:

Tan pronto como esta multitud es así reunida en un cuerpo, no se puede ofender a uno de sus miembros sin atacar al cuerpo, y aún menos atacar al cuerpo sin que los miembros se resientan (...) En efecto, cada individuo puede como hombre tener una voluntad particular contraria o diferente a la voluntad general que tiene como ciudadano (...) Así, y para que el pacto social no sea una vacua fórmula, encierra tácitamente este compromiso, único que puede dar fuerza a los demás, de que quienquiera que se niegue a obedecer a la voluntad general será obligado por el cuerpo entero: lo que no significa otra cousa sino que se le forzará a ser libre?

Que la libertad pueda o incluso deba ser impuesta, resulta a priori paradójico. Y no obstante así es ${ }^{8}$, como también paradójicamente la tolerancia sólo es concebible en virtud de una imprescindible connivencia con una radical intolerancia hacia todo aquello que pueda amenazar el régimen de convivencia sobre el que aquélla se sustenta y al cual, recíprocamente, ella misma sustenta.

Este vaivén entre prácticas tolerantes e intolerantes complementarias se hace evidente cuando contemplamos los discursos de los más destacados teóricos de la tolerancia. Tomemos, a modo de ejemplo, tres casos particularmente significativos de la Modernidad ilustrada: Locke, Kant y el propio Voltaire, ya mencionado. Comencemos por el primero de ellos. El autor de la Carta sobre la tolerancia comienza su discurso repugnando la intolerancia de quienes, en nombre de la religión, agreden al prójimo. El argumento es contundente, pues para desligitimar las actitudes intolerantes Locke echa mano de los propios principios sustentantes de las religiones en nombre de las que se agredería. En consecuencia, continúa el argumento, podemos decir que la tolerancia es, para el caso, en realidad un principio que emana del propio cristianismo.

Aunque, claro está, no sólo de él: «[la] tolerancia a favor de los que difieren de los demás en materia de religión es tan conforme con el evangelio de Jesucristo, y con el sentido común [genuine reason] de todos los hombres, que puede mirarse como cosa monstruosa que haya gentes bastante ciegas como para no ver la necesidad y beneficios de ella ${ }^{9}$. A pesar de que pueda mostrarse como tal, la religión no es el verdadero sustento de la tolerancia; ésta reposa, en última instancia, sobre la legítima razón humana, que determina tanto el ejercicio de la tolerancia como el de la fe religiosa ${ }^{10}$.

\footnotetext{
Rousseau (1964), pp. 363-364.
}

8 Hablamos de paradoja, y no de contradicción, pues desde la perspectiva adoptada por Rousseau efectivamente no constituye una contradicción que la libertad se consume en virtud de una complementaria imposición. Al contrario, la propia concepción moderna de libertad, según la cual el individuo puede sustraerse tanto a la necesidad de la naturaleza como a lo arbitrario de su libre arbitrio particular, comporta esa misma complementariedad.

$9 \quad$ Locke (1999), p. 11; (1991), pp. 16-17.

10 Si bien es cierto que Locke vincula la fundamentación de la sociedad civil, y con ésta el ejercicio de la tolerancia, a la suprema autoridad del «Creador [Maker]» o «Señor soberano [sovereign Master]» (vid. Locke 2005, p. 20), lo hace desde una teología natural que sanciona la instauración de los «Intereses civiles» como existentes «ya 
En términos muy semejantes refiere Kant su concepción de la tolerancia, por mucho que en sus palabras podamos sospechar, inicialmente, algo diferente. Leemos así en uno de los más célebres escritos kantianos que «un príncipe que no considera indigno de sí reconocer como un deber suyo el no prescribir a los hombres nada en cuestiones de religión, sino que les deja plena libertad para ello e incluso rehúsa el altivo nombre de tolerancia, es un príncipe ilustrado y merece que el mundo y la posteridad se lo agradezcan ${ }^{11}$.

¿Altiva, nada menos que la tolerancia? Parecería que Kant se situase en las antípodas de Locke, y sin embargo esencialmente coinciden. La acusación kantiana debemos entenderla en clave de contraposición entre la arrogada autoridad de un sujeto que ejercería su benévola tolerancia particular, y la legítima, que pasaría por el previo reconocimiento de que sólo en virtud del soberano tribunal de la razón se puede ejercer la autoridad, con lo que realmente no sería necesario el recurso a tal tolerancia. La acusación se orienta hacia aquellos soberanos que, en tiempos de permanentes conflictos religiosos, tenían la potestad de mostrarse soberanamente tolerantes hacia prácticas religiosas divergentes. Kant comparte con Locke que, pese a lo beneficioso que pueda resultar un ejercicio de la tolerancia por parte de las religiones, en las que encontramos una tolerante llamada a una superación de toda confrontación, es en última instancia sobre la "legítima razón humana", y sólo sobre ella, que puede descansar toda-legítima-autoridad. Podríamos pues decir que Kant sólo nos marca de forma más clara la línea divisoria entre lo público y lo privado, lo comunitario y lo individual ${ }^{12}$, cosa que, por lo que respecta a la tolerancia, separa su concepción temprana en los albores de la Modernidad de la madurez ilustrada en la que se culminará el concepto.

Nuestro tercer ejemplo es Voltaire, autor también de un texto de referencia en la literatura sobre la tolerancia. En él encontramos un discurso que no se distancia apenas de lo visto en los dos anteriores:

Nuestras historias, nuestros discursos, nuestros sermones, nuestras obras de moral, nuestros catecismos, respiran todos, enseñan todos hoy ese deber sagrado de la indulgencia. ¿Por qué fatalidad, por qué inconsecuencia desmentiríamos en la práctica una teoría que predicamos todos los días? Cuando nuestras acciones desmienten nuestra moral es porque creemos que hay alguna ventaja para nosostros en hacer lo contrario de lo que enseñamos; pero desde luego que no hay ninguna ventaja en perseguir a aquéllos que no son de nuestra opinión, y en hacernos odiar. Hay, pues, una absurdidad en la intolerancia ${ }^{13}$.

Con otras palabras, la tolerancia es (lo) racional. Voltaire refiere aquí la misma transición de una reivindicación particular de la tolerancia a la racionalidad que, en última instancia, la sostiene y legitima, haciendo de esa misma práctica particular un mero ejemplo de algo que, por su racionalidad, tiene en realidad valor universal ${ }^{14}$.

en el estado de naturaleza, donde surgen como derechos de la naturaleza racional y sociable de los hombres» (Hunter 2011, p. 134).

$11 \quad$ Kant (2004), p. 91.

12 Y con ello, entre razón y religión.

13 Voltaire (1961), p. 620.

14 Tanto es así que el propio Voltaire afirma haber redactado su escrito sobre la tolerancia al dictado de la propia naturaleza humana (ibid., p. 645). 
Nada nuevo. Mas sí nos sirve este pequeño fragmento para poner de relieve la misma cuestión que señalábamos anteriormente a propósito de la referencia a Marcuse, a saber, la circunscripción de la práctica de la tolerancia a un determinado sujeto depositario de la hegemonía desde la que ésta se asimila. «Nuestras historias, nuestros discursos, nuestros sermones, nuestras obras de moral, nuestros catecismos», escribe enfáticamente Voltaire. Debemos ser indulgentes, y de ahí tolerantes, porque nuestras creencias, nuestros preceptos, en definitiva, nuestros principios, nos impulsan a ello, haciendo que resulte desventajoso para nosotros caer en la absurdidad de hacer nuestra acción inconsistente con nuestros principios. Tal vez la chocante vinculación que Kant hacía de tolerancia y altivez tenga más sentido del que parecería en un principio.

De hecho, si definimos la tolerancia como la disposición a aceptar opiniones o conductas con las que uno no está de acuerdo y que podría no aceptar, debemos inferir que su práctica implica necesariamente una posición de autoridad ${ }^{15}$. Es esto lo que la acusación de Kant pone de manifiesto: tolerar supone autoridad ${ }^{16}$. Ahora bien, la solución kantiana, supuestamente superadora de la pretenciosidad denunciada, no suspende en realidad este principio de autoridad, sino que lo desplaza, substituyendo la autoridad del sujeto tolerante por otra, la de la razón, pretendidamente impersonal y universal. En lugar de la soberanía del princeps particular sitúa Kant la soberania de los principia universales; mas, como se puede entrever en las mismas palabras de Voltaire, los principios serán siempre nuestros principios, y en consecuencia, su universalidad, dudosa. Quizás la substitución no tenga el alcance que se le supone, pues como explica José Gaos:

La definición de la Filosofía por medio del concepto de "principio", "arquetípica" en y desde Aristóteles, y este concepto, son reveladores: "ciencia de los principios". "Ciencia", documentando lo dicho acerca de los filósofos como hombres de ciencia; pero “de los principios", revelando la diferencia entre los filósofos y los hombres de ciencia no filósofos. "Principios" traduce "arché". Esta palabra griega es de la familia de la palabra "arconte". "Principio" es palabra de la familia de las palabras "principal" y "príncipe". Los principios "principiaron" por ser los príncipes concretos antes de ser los principios abstractos: los patriarcas al frente, en sentido propio y figurado, de sus familias, esclavos y rebaños. Esta historia semántica la comparten otros principales términos filosóficos: "naturaleza", "causa"... Príncipe es, pues, el primero y principal, el dueño y señor. Principio es - un príncipe abstracto, pero todavía primero y principal, dueño y señor. ¿De qué? De lo "principiado" por él. Principio es esencialmente principio de-lo principiado por él. Cuando los "principios" son los verdaderos, los literales "principios", los "primeros principios", expresión perfectamente pleonástica, son los principios de -todo lo demás. Ahora bien, los filósofos son los hombres de los principios, los conocedores y los dueños de éstos, y por medio de ellos, de todo lo demás, pero particularmente de los demás

15 Si no existe la posibilidad de rechazar una opinión o conducta, es evidente que no podemos hablar de tolerancia. En tal caso, procedería hablar más bien de resignación. De hecho, la propia etimología de la palabra lo evidencia, pues tolerantia nos remite a tolero, cuyo significado es el mismo que el del tallo griego del que se origina, a saber, "soportar"; y uno no puede soportar nada si no tiene la fuerza (poder) para hacerlo.

16 La denuncia kantiana de la pretenciosa tolerancia se asemeja mucho al desprecio que Voltaire hace de la caridad, a la que califica de «mezquina e insultante» (Voltaire 1961, p. 649). En ambos casos se evidencia un rechazo de una arrogante posición de autoridad implícita en la condescendencia hacia aquél sometido en una relación desigual. 
hombres, sus congéneres, más interesantes de dominar que la naturaleza misma -para los hombres afanosos de dominación, los "hombres de poder". Cuando el principio es el sujeto trascendental, el filósofo es, o el sujeto trascendental mismo, o, más que el mero conocedor de él, el creador de él y consiguiente dueño de él, o el aniquilador de él y no menos dueño de él -y por medio de él, o incluso de la aniquilación de él, de todo lo demás ${ }^{17}$.

Vemos así cómo la cuestión de la tolerancia encierra otra, más de fondo: la de la subjetividad. Más allá de las diferencias que podamos identificar en la defensa de la tolerancia de estos tres referentes del pensamiento ilustrado, encontramos una concepción afín del sujeto que la sostiene, a saber, un sujeto racional, un yo que se constituye sobre un principio que en última instancia él mismo proporciona o descubre en sí, y con ello puede posteriormente ejercer, también racionalmente, sus prácticas de tolerancia, cuyos límites estarán claramente definidos, pues basta con remitirse a la autoridad del tribunal de la razón ${ }^{18}$, esto es, la misma que hace que el sujeto sea lo que es. Aquello que nos permite decir "yo", ontológica o políticamente, es lo que nos permite ejercer una tolerancia para la cual no existe problema alguno relativo a límites o legitimación, precisamente porque en ambos casos subyacen unos mismos fundamentos que erradican cualquier problema. Los límites de lo tolerable son, pues, los límites del yo como sujeto constituido racionalmente - en base a "nuestros principios", como afirma Voltaire"

\section{Tolerancia activa, o la búsqueda del yo ante el otro}

En el caso que acabamos de referir, la práctica de la tolerancia-que hemos delimitado calificándola como pasiva ${ }^{20}$ - se sostiene sobre una determinada concepción del sujeto, la de un yo que se antepone al ejercicio de la tolerancia y que es, mediante éste, doblemente ratificado: por un lado, en tanto que aquello que lo fundamenta es lo mismo que fundamenta la práctica de la tolerancia, a saber, determinados principios racionales establecidos; por otro lado, en tanto que esta misma práctica

17 Gaos (1982), p. 400.

18 Una razón, por ejemplo en el caso de Locke, sancionada desde una determinada religiosidad (vid. supra nota 9), lo cual, lejos de relativizarla, corrobora su valor absoluto.

19 O como hace también, en términos muy semejantes, Locke. "Nuestros principios" son, ante todo, la voluntad general o el bien común, como ya hemos señalado. Locke lo expresa con claridad cuando afirma que «[e]1 Estado [commonwealth], según mis ideas, es una sociedad de hombres instituida con la única mira del establecimiento, conservación y desenvolvimiento de sus intereses civiles» (Locke 1999, p. 112; 1991, p. 17), los cuales legitiman tanto la práctica de la tolerancia como de una legítima violencia que pueda impedir toda amenaza (vid. ibid.). No debemos pasar por alto que cuando Locke habla de derechos fundamentales contempla también el controvertido derecho a la propiedad privada, revelador de la consagración de un yo individual que es producido y protegido por determinadas políticas de la subjetividad y la tolerancia. Tal vez con más claridad lo comprobamos en la obra de John Stuart Mill, quien de algún modo representa la culminación de esta misma concepción. Mill defiende que debe existir un ámbito de acción individual libre de toda interferencia por parte de la sociedad, y así la coerción, como límite de la tolerancia, sólo es legítima para garantizar la protección de los sujetos, soberanos en su individualidad, y en ningún caso en nombre de un bien común (vid. Mill 2003, pp. 94ss).

20 Sólo podemos estar parcialmente de acuerdo con Victoria Camps cuando afirma que "“tolerar" significa "soportar", "aguantar", un ejercicio "pasivo"» (Camps 1990, p. 86). Si bien tolerare significa en latín "soportar", una posible equivalencia en griego sería phoreo, cuya traducción puede ser tanto "llevar sobre sí" como "ser arrastrado". Valga la cuestionable referencia etimológica como mera insinuación de otras posibles lecturas del léxico que soporta el concepto. 
permite confirmar la identidad particular del yo que la ejerce. Cada vez que alguien tolera algo produce así una doble confirmación: de la tolerancia ("desapruebo eso, pero es tolerable") y de sí mismo ("no me identifico con eso, y no obstante, sí me identifico como tolerante al soportarlo"). Así entendida, la tolerancia funciona como un dispositivo de armoniosa confrontación de sujetos previamente constituidos ${ }^{21}$; facilita un marco en el que refrendarse a sí mismo por medio de un racional y cívico distanciamiento o incluso rechazo del otro ${ }^{22}$.

Claro que esto implica, como es obvio, la identidad de un yo, que en la práctica de la tolerancia se asume como ya dado y ésta última simplemente reafirma. La identidad existe antes del ejercicio de la tolerancia; antes, en un orden lógico y jerárquico: es en todos los sentidos primera, en tanto que es al principio y es por principio, como hemos mostrado.

Ahora bien, ¿podemos invertir los términos, de manera que sea la tolerancia la que tenga anterioridad, si no jerárquica, sí al menos lógica? Hablamos, en tal caso, de una práctica que no presupone la identidad de un yo, sino que, al contrario, la suspende en favor de un ejercicio primero de la tolerancia que pueda servir, justamente, para producirla; que no supone sino que pospone un yo. Es lo que podemos denominar "tolerancia activa" ${ }^{23}$, y encontramos, ejemplarmente, en la obra de Gotthold Ephraim Lessing.

Además de ser reconocido como un referente de la Aufklärung germana, Lessing destaca también por ser considerado uno de los mayores apóstoles de la tolerancia. Esta consideración se le debe, muy particularmente, a su drama Nathan el sabio, en el que reivindica la posibilidad de una conciliación de las tres religiones abrahámicas fundada en un ejemplar ejercicio de tolerancia ${ }^{24}$. La importancia del Nathan respecto de la cuestión que nos ocupa se debe a más de un aspecto que debemos considerar: por un lado, el modelo ejemplar que en la obra nos presenta la persona del sabio Nathan; por otro, el hecho de que Lessing, para mostrarnos su ideal de tolerancia ilustrada, recurra, curiosamente, a un marco premoderno ${ }^{25}$.

21 Armoniosa diríamos hasta cierto punto: el carácter absoluto que adquieren los principios fundamentantes puede implicar un no menos absoluto rigorismo en su aplicación. Véase, por ejemplo: Kant (1989), p. 173.

22 Una tolerancia así concebida constituye la perfecta aliada del binomio: íntimo desprecio/pública aceptación del otro. "Vicios privados, virtudes públicas". La polémica obra de Bernard Mandeville La fábula de las abejas, inspiradora del más acérrimo liberalismo consagrador de un radical egoísmo, se nos insinúa en este punto como una derivación no ya de los mismos principios del liberalismo de Locke, sino, más aún, de una misma concepción del sujeto.

23 En términos semejantes distingue Peter Nicholson un ejemplo "negativo" y otro "positivo" de la tolerancia; de éste último diferencia, a su vez, dos perspectivas, siendo la segunda, «más fuerte», la que más se aproxima a lo que aquí argumentaremos como la representada por Lessing. Es significativo que Nicholson diga, a respecto de esta última forma de tolerancia, que sirve para que uno sea «instruido y educado» (Nicholson 1985, pp. 163ss).

24 A pesar de que, como señala W. Goetschel, la palabra "tolerancia" sólo aparece una vez en el texto y el propio drama es crítico hacia el discurso de la tolerancia (Goetschel 2005, p. 200), seguramente -añadimos nosotrosporque, como veremos, es otra tolerancia la que está en juego.

25 A estos aspectos habría que añadir, al menos, un tercero, como es que Lessing opte para su presentación por «el viejo púltpito del teatro» (Fischer y Fox 2005, p. 32), en lugar de otras alternativas como podrían ser, sin ir más lejos, los célebres Tratado y Carta de Voltaire y Locke, respectivamente. No hay espacio para tratar aquí una cuestión que demanda una mayor atención, como es el privilegio de un discurso dramático. Es evidente que la opción escogida por Lessing está cargada de intencionalidad, y supone una clara decisión de rechazar la -impropia- autoridad de un discurso teórico en favor del drama como medio que incita la incorporación de aquél que a él asiste, o sea la praxis, que, como señala Karl Barth, constituye para Lessing «el sentido más profundo de la vida humana» (citado por Agustín Andreu: Lessing 1982, p. 156). A este respecto, es relevante recordar cómo Lessing, en la Dramaturgia de Hamburgo, reivindica un nuevo teatro para Alemania que pueda recuperar las viejas prácticas del teatro clásico, en que griegos y romanos se sentían arrebatados, dominados (iy 
Antes de dar paso a estas cuestiones debemos situar el drama de Lessing, el cual surge, una vez más, en un contexto de conflicto religioso, como también en el pasado las guerras de religión habían ocasionado la respuesta de la tolerancia como un pragmatismo de estado, tal como la concebía Jean Bodin ${ }^{26}$. En este caso, el conflicto es el que tiene lugar entre las tesis deístas de Hermann Samuel Reimarus y la ortodoxia luterana, en defensa de la cual saldrá el pastor Johann Melchior Goeze. Reimarus, profesor de lenguas orientales en Hamburgo, había publicado en 1754 Las verdades capitales de la religión natural, obra en la que reclamaba la necesidad de que la razón se abra al camino de la fe para extenderse en la dirección de la revelación propia de las religiones del libro, así como que la propia revelación pase entonces el escrutinio de la razón. Años más tarde escribiría una segunda obra, Apología o alegato en defensa de los racionales devotos de Dios, donde profundizaba en su exposición de las mismas tesis, denunciando la intolerancia con la que éstas eran recibidas, lo que evidenciaba la pérdida por parte del cristianismo de sus necesarias raíces racionales, así como la consecuente debilidad de una fe cuestionable, pues la verdadera fe está racionalmente fundada y no teme confrontación con la razón ${ }^{27}$.

Mientras que el primero de estos textos saldría a la luz de la mano de su autor, el segundo quedaría inicialmente inédito, hasta que, entre 1774 y 1778, lo diese a conocer Lessing publicándolo por medio de extractos, ya muerto Reimarus y sin desvelar su autoría. A ello respondería rápida y contundentemente Goeze, portavoz de una autoritaria ortodoxia luterana. Con ello se originaría la conocida como Fragmentenstreit, tal vez la polémica teológica más importante del XVIII alemán que enfrentaba la teología luterana con las aspiraciones de la razón ilustrada.

En este contexto surge el Nathan como respuesta de Lessing al conflicto, abanderando el criterio de una toleranci ${ }^{28}$ que se distancia tanto de la pretenciosidad de una posición que se arrogue el privilegio de imponerse sobre otra, como de la solución consistente en apelar a una soberanía trascendental que resuelva el conflicto subsumiendo las distintas posiciones a la autoridad suprema de una razón universal, desplazando al indecidible ámbito de la interioridad la propia experiencia de la revelación ${ }^{29}$.

La tolerancia del sabio judío Nathan equivale a la de su autor, que entra en el conflicto entre deísmo y ortodoxia luterana con el ánimo de elevar la cultura alemana sobre el provincianismo, la religiosidad infantil y la unilateralidad racionalista en

educados!) por las vivas sensaciones recibidas desde la escena, por contraposición a germanos y franceses, fríos e indiferentes ante una escena que no provoca otra cosa que una distante espectación, a la que se asiste «por curiosidad, por moda, por aburrimiento, por socializar, por el deseo de ver y hacerse ver» (Lessing 1970-79, vol. 4, p. 602). No hay duda de que la llamada a la creación de un teatro para un pueblo que "aún no lo tiene" (vid. id.) es inseparable de la decisión de tratar mediante un drama el ideal pedagógico de la tolerancia.

26 Véase el completo estudio de Forst (2013), pp. 138ss. Puede compararse la concepción de Bodin con la valoración que Montaigne hace de la tolerancia como una neutralización de un otro que me amenaza (cf. Levine 2001, pp. 193ss).

27 Para la recepción del deísmo de Reimarus se pueden consultar las páginas que le dedica Forst en su trabajo (op. cit., pp. 299ss). También se puede ver el estudio introductorio de Agustín Andreu a su tradución del Nathan (2008).

28 A pesar de que hablemos de un sentido "activo" de la tolerancia, es evidente que en el mismo contexto en que Lessing reivindica su ejercicio predomina su sentido "pasivo" (cf. supra nota 24), como así se pone de manifiesto en la propia definición de la voz Tolerantz recogida en la vasta enciclopedia de Johann Heinrich Zedler, contemporánea al propio Lessing (Zedler 1731-54, vol. 44, pp. 1115-1117). También es relevante, a respecto de lo que nos ocupa, que en ésta la tolerancia se vincule expresamente al ámbito de lo religioso.

29 Sobre las relaciones entre razón y revelación, véase: Kant (1995), pp. 150ss. 
la que se encuentra ${ }^{30}$. Lessing es, él mismo, ejemplo de tolerancia, a medio camino entre las tesis deístas de Reimarus y la caduca defensa de la ortodoxia luterana por parte de Goeze. Al mediar discursivamente ${ }^{31}$ en el conflicto externo, Lessing exterioriza el conflicto interno de la fe, haciéndolo manifiesto como vía para su necesaria resolución. Decimos que Lessing es ejemplo de tolerancia porque no se alinea sin más con las tesis deístas de Reimarus, pese a difundirlas, ni se identifica con la ortodoxia luterana de Goeze, como es más evidente en la propia polémica. Opta, en su lugar, por una posición intermedia, que llegue hasta el fondo de la controversia para abordarla de la mano de una tolerancia que no es estrategia para asumir la coexistencia de posiciones enfrentadas, sino medio para conciliarlas, disolviendo la confrontación en un punto de encuentro que está por venir. Es decir, la apuesta por la tolerancia no equivale a un intento de mediación, sino que va más allá, mostrándose como la manifestación de una demanda de reconfiguración de la subjetividad, cuestionada en el encuentro con el otro.

Para ello, una tolerancia activa es la clave. Es revelador que Lessing denuncie la «salvaje ortodoxia» por no permitir la tolerancia ${ }^{32}$, al mismo tiempo que evita alinearse con el deísmo de Reimarus por, justamente, una cuestión de tolerancia: «nuestros deístas quieren ser tolerados sin ninguna condición. Quieren tener la libertad de impugnar la religión cristiana $\mathrm{y}$, no obstante, ser tolerados ${ }^{33}$.

La denuncia de Lessing parecería evocar la demanda que Voltaire pone en boca de un mandarín, alegoría de la tolerancia, para el caso. En el Tratado sobre la tolerancia, éste, ejerciendo de intermediario en una polémica entre un dominico y un jesuita, llama la atención sobre la necesidad de practicar la tolerancia con un tan simple como contundente «si queréis que se tolere aquí vuestra doctrina, comenzad por no ser vosotros ni intolerantes ni intolerables $»{ }^{34}$. Sabio punto de partida, que parece coincidir con la postura de Lessing, si bien Voltaire está, en realidad, en sus antípodas. Lo comprobamos cuando continuamos la lectura del texto:

La discusión se acaloró, el dominico y el jesuita se agarraron por los pelos. El mandarín, informado del escándalo, mandó a los dos a la cárcel. Un submandarín dijo al juez: “¿Cuánto tiempo quiere Vuestra excelencia que permanezcan encerrados?” "Hasta que se pongan de acuerdo”, dijo el juez. “¡Ah!”, dijo el submandarín, “entonces se quedarán en la cárcel toda la vida". "Pues bien", dijo el juez, "hasta que se perdonen". "No se perdonarán jamás”, le replicó el submandarín; “los conozco bien”. “¡Bueno!”, dijo el mandarín. "Entonces, hasta que finjan perdonarse" 35 .

La solución final es, para Voltaire, el fingimiento de una aceptación mutua que nunca podrá tener lugar entre sujetos inamovibles en sus convicciones íntimas, y sólo maleables en sus comportamientos externos. Un claro ejemplo de la contraposición de interioridad y exterioridad en la que se decide una tolerancia pasiva ${ }^{36}$. Muy por

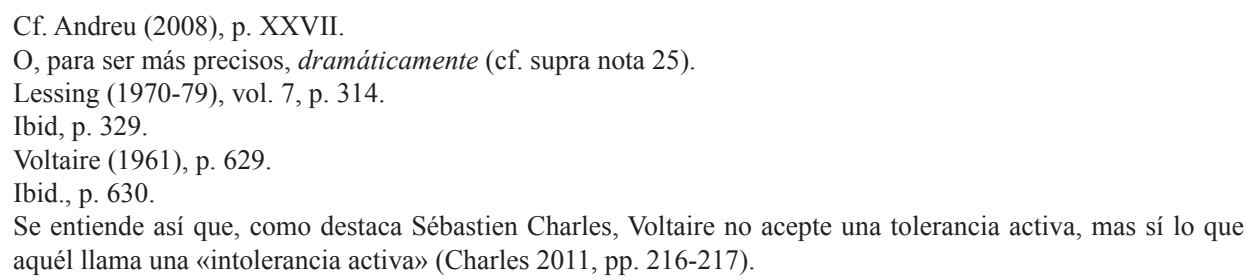


el contrario, para Lessing la solución pasa por un encuentro íntimo que alcance al propio sujeto, y que solo se producirá en virtud de una búsqueda de sí en el mismo desencuentro, que la tolerancia, lejos de neutralizar, ofreciendo al sujeto un espacio para encerrarse sobre sí, promueve y resuelve.

Volviendo a la polémica que ocupa a Lessing, su distanciamiento de Reimarus o de Voltaire, mutatis mutandis - responde al reconocimiento de la revelación, que tiene un papel esencial que el deísmo no contempla. Como nos explica en detalle en La educación del género humano, la revelación posee una función educadora ${ }^{37}$ que es necesario integrar si no se quiere caer en la unilateralidad de una pretenciosa razón encerrada arrogantemente en sí misma. Razón y revelación deben complementarse dialógicamente (activamente), y no limitarse a gestionar sus fronteras (pasivamente) ${ }^{38}$. Así, Lessing se distancia de una posición más reconociblemente ilustrada en la que el deísmo encuentra su perfecto acomodo, y lo hace al cuestionar la contraposición revelación/razón como equiparable a la que separaría lo público de lo privado ${ }^{39}$.

En el fondo yace una concepción del sujeto, la cual distingue claramente interioridad de exterioridad. Mas Lessing muestra que tal distinción no se sostiene; puede argumentarse, teóricamente, pero se desmorona en su aplicación práctica. No sólo porque implica una cesura esquizofrénica, sino porque resulta manifiestamente problemático fijar una demarcación que separe ambos ámbitos ${ }^{40}$; o porque la razón pura, como soberana en el ámbito de lo público, carece de la necesaria confrontación que pueda cuestionarla o ratificarla ${ }^{41}$; o porque evidencia la falacia oculta en una tolerancia que descanse sobre tal contraposición público/privado. En definitiva, la improcedencia que Lessing hace ver pone en evidencia la necesidad de volver sobre el sujeto no como algo ya dado, sino como algo aun por realizarse en el marco dialógico de la contraposición interioridad/exterioridad, razón/revelación.

Muy lejos de una tolerancia que sirva de refugio para un sujeto entregado a la consagración de su individualidad, y con ella de un marco de colectividad en el que

37 «Lo que la educación es para el individuo, es la revelación para el género humano» (Lessing 1970-79, vol. 8, p. 490).

38 Cf. ibid., pp. 552, 560. Con otras palabras, para Lessing debe salvarse la religión de la teología, lo que equivale a reconocer la primacía de la praxis sobre la mera teoría. Tal como expone en su temprano escrito Pensamientos sobre los Herrnhuter: «cómo el cristianismo práctico [ausübende] fue disminuyendo día a día, mientras que el contemplativo [beschauende] se elevaba, mediante fantasías y humanas expansiones, a un nivel al que la superstición jamás llevó a ninguna religión. Todo dependía de uno, que más se equivocaba cuanto con más seguridad podía hacerlo» (ibid. vol 3, p. 687). La consigna es así un socrático « Volved la mirada hacia vosotros mismos!» (ibid., p. 684), esto es, trabajar la propia identidad del sujeto por medio del encuentro con el otro: tanto el otro que se encuentra ante uno como lo otro que la revelación es para la razón. Para entender cómo se debe reconsiderar la relación entre éstas puede consultarse Sobre la demostración en espíritu y fuerza (ibid, vol. 7, pp. 946ss).

39 Piénsese, por ejemplo, en Voltaire, quien defiende que las leyes velan sobre lo público y la religión sobre lo privado (Voltaire 1961, p. 630).

40 Ya lo anticipamos al hacer referencia a Mill como momento culminante de esta concepción (vid. supra nota 19). Camps habla expresamente de la vaguedad de la propuesta de Mill, que se explicaría por su interés en fijar límites a la sociedad, no al individuo (Camps 1990, pp. 78-79).

${ }^{41}$ Sin movernos del mismo marco histórico, podemos pensar en las críticas del jesuita Nonnotte, némesis de Voltaire, al que reprocharía «que los filósofos, arremetiendo contra las persecuciones, excluyen y justifican siempre las hechas a la religión» (Nonnotte 1773, p. 148). Dejando a un lado la debilidad de muchos argumentos de Nonnotte, superficialmente apologéticos, encontramos en su tenaz ofensiva a Voltaire una evidencia de la paradoja de la tolerancia a la que ya hemos referido, en tanto que identifica al ilustrado como un gran perseguidor de las persecuciones no perseguido (vid. ibid., p. 141), expresión en sí misma paradójica que podríamos iluminar con la lectura de Marcuse. Lo evitaremos, pues implicaría desviarnos a otras discusiones, en la medida en que el propio Voltaire nos ofrece ora un perfil abiertamente antidogmático, ora otro aparentemente más resoluto. 
ésta pueda ejercerse sin riesgos, Lessing reconoce en el encuentro con el otro un momento constitutivo del sujeto, siendo la tolerancia no un medio para evitarlo sino, inversamente, la garantía de que el encuentro sea realmente tal, y no un simulacro que no llega a alcanzar la interioridad de ambos. En consecuencia, no sorprende que para ilustrar su modelo de tolerancia se distancie del contexto inmediato para remontarse, curiosamente, a los tiempos prerrenacentistas, mirando en el espejo de dos grandes referentes como son el sultán Saladino (intratextual) y Boccaccio (extratextual); dos modelos premodernos para tiempos de cegadoras luces.

Si Saladino es la figura que acompaña al judío Nathan en la obra, Boccaccio es la que la contagia de la filosofía humanista del Renacimiento, representada por el Decamerón ${ }^{42}$. Y si el texto de Boccaccio determina el espíritu del texto, la parábola de los tres anillos constituye la perfecta analogía de la concepción de la tolerancia que se nos ofrece. Como es sabido, la parábola que Lessing toma del Decamerón es utilizada por Nathan como respuesta a la comprometida pregunta de Saladino, que desea saber nada menos que cuál de las tres religiones abrahámicas es la verdadera. A ello Nathan responde con la conocida parábola, sobre un padre que entrega a sus tres hijos su anillo y dos copias perfectas del mismo, indistinguibles, al ser incapaz de decidir a cuál de los tres ha de legar el auténtico ${ }^{43}$.

La respuesta de Nathan es clara: igual que no hay modo de saber cuál de los tres anillos es el verdadero, también es imposible saber cuál de las tres religiones es la verdadera. En la versión del propio original de Boccaccio:

Y lo mismo os digo, mi señor, de las tres leyes dadas a los tres pueblos por Dios padre sobre las que habéis planteado la cuestión: cada uno su herencia, su ley verdadera y sus mandamientos cree tener y cumplir; mas quién la tenga, como de los anillos, es cuestión que aún está pendiente. ${ }^{44}$

Lejos de lo que pudiera ingenuamente parecer, la parábola no es una ingeniosa táctica para eludir la respuesta. Lessing lo entiende bien, de igual modo que entiende y asume el presupuesto implícito en ésta, que no es otro que la escéptica convicción de que la verdad por la que Saladino pregunta es algo que debe ser buscado, y no algo que pueda ser sin más entregado. El propio Nathan lo manifiesta cuando, momentos antes de encontrarse con Saladino, reflexiona para sí:

¿Qué me pasa? - ¿Qué quiere el sultán? ¿Qué? - Yo estaba preparado para dinero; y él quiere - verdad. ¡Verdad! Y la quiere tan, - tan simple, tan pura, - ¡como si la verdad fuese moneda contante! - Sí, ¡si aún fuese una moneda antigua de las que se sopesaban! ¡Eso aún! Pero una moneda nueva, hecha por mera acuñación, de las que sólo se pueden contar en el mostrador, jeso no es verdad, en absoluto! Igual que el dinero en el bolso, ¿se metería también la verdad en la cabeza? ${ }^{45}$

Al diálogo entre revelación y razón, entre exterioridad e interioridad, se suma ahora el problema de la verdad como cuestión última a la que nos remite la parábola.

42 John Owen define el Decamerón de Boccaccio como «vademecum del Renacimiento» (citado por Andreu 2008, p. XXX).

43 Vid. Lessing (1970-79), vol. 2, pp. 276ss.

44 Boccaccio (1956), p. 47 (énfasis añadido).

45 Lessing (1970-79), vol. 2, pp. 274-275. 
A este respecto Lessing se nos revela como un escéptico: no en el sentido de que niegue toda verdad, sino en un sentido más propio, según el cual la verdad está sujeta a una búsqueda permanente, lo que la vincula al ámbito de la praxis. Es en la misma búsqueda y en la eventual realización por parte del sujeto que la verdad tiene lugar. Lessing lo hace explícito en uno de sus más celebrados fragmentos, correspondiente a Una réplica («Sobre la verdad»):

No es la verdad, en cuya posesión uno está o cree estar, lo que constituye el mérito del hombre, sino el honesto empeño que ha hecho en llegar a ella. Pues no por la posesión sino por la búsqueda de la verdad se incrementan sus fuerzas, y sólo en ello estriba su siempre creciente perfección. La posesión nos hace cómodos, indolentes, orgullosos.

Si Dios tuviese en su mano derecha toda la verdad y en su izquierda el único y siempre cambiante impulso [Trieb] hacia la verdad, incluso con el añadido de siempre y eternamente errar, y me dijese: ¡escoge! Me pondría humildemente de rodillas a su izquierda y diría: ¡dame, Padre! ¡La pura verdad es sólo para ti! ${ }^{46}$

Este mismo fundamento escéptico lo encontramos en la parábola ${ }^{47}$. Es fácil interpretarla en la clave en que, por ejemplo, Voltaire describe el lugar que debe ocupar la religión ${ }^{48}$, a saber, no importa qué validez externa (objetiva) tenga lo religioso, ya que su función (subjetiva) consiste en regular internamente la vida del individuo, y en el ámbito de la interioridad, consagrador de la individualidad del sujeto, los principios que regulan la vida social (principios objetivos, externos, públicos) no tienen cabida, justamente por ser ése el dominio subjetivo que debe ser respetado. Así, la verdadera fe sería un asunto exclusivo de la interioridad, que es lo que expresaría la parábola al hacer indecidible externamente la verdad de cada anillo. Mas no es esto lo que Lessing nos dice. Al contrario, lo rechaza y supera, porque no acepta que se dé en el sujeto una cesura como la de interioridad/exterioridad que acoja de la razón/revelación. Justamente el rechazo de dicha contraposición es lo que está en juego en la parábola. Preguntemos de nuevo: ¿cuál será el anillo verdadero? No hay modo de saberlo viéndolos, pues son idénticos. Ahora bien, sí existe una manera de resolver la cuestión, que apunta el juez al que se le encarga la resolución de la disputa:

¡Pero espera! Dicen que el auténtico anillo posee el maravilloso poder de hacerse querido; ante Dios y los hombres ser grato. ¡Eso debe decidir! Pues los anillos falsos no podrán hacerlo. - Veamos, ¿quién de vosotros es el más amado por los otros dos? - ¡Venga, decid! ¿Calláis? ¿Los anillos sólo actúan hacia dentro? ¿Y no hacia fuera? ¿Cada uno sólo se ama ante todo a sí mismo? - ¡Oh, entonces sois los tres engañadores engañados! Vuestros anillos son falsos los tres. ${ }^{49}$

En consonancia con el rechazo de la verdad como moneda acuñada que se pueda dar sin más, la verdad de la revelación no permite hacerse efectiva si no es en virtud

$46 \quad$ Ibid., vol. 8, p. 33.

47 En este sentido, podríamos considerar un precedente Los judios, un anterior drama donde Lessing relaciona la actitud tolerante con su desconfianza en el dogma y el sistema, lo que le lleva a favorecer un cierto eclecticismo filosófico (vid. Nisbet 2005, 136).

48 Vid. supra nota 38.

49 Lessing (1970-79), vol. 2, p. 279 (énfasis añadido). 
de su manifestación en la propia acción del individuo. Al hacer decidir la verdad de la fe en los actos «hacia fuera», Lessing echa por tierra la distinción, típicamente ilustrada, entre lo interior y lo exterior como dominios en que se decide no sólo la subjetividad, sino también un posterior ejercicio de la tolerancia. No es posible atender a la intimidad de la fe sin salir al mundo mediante una acción moral en la que lo que ha sido revelado se revele: en su verdad. Lessing rechaza una paroxística versión de la subjetividad moderna perdida en una ebriedad del yo, reclamando, en su lugar, la confrontación de éste con su propia salida al mundo, en virtud de la cual podrá constituirse. Y es que «una cosa es sospechar, desear, creer en la inmortalidad del alma como en una especulación filosófica, y otra cosa es orientarse en la actividad interior $y$ exterior de acuerdo con esa doctrina» ${ }^{50}$.

La prueba de que Lessing se inclina decididamente por esto último la encontramos en la propia parábola, que sólo ingenuamente podría ser vista como un alegato en favor del valor subjetivo, intimista, de la fe. Muy al contrario, la parábola que Nathan presenta a Saladino es una defensa manifiesta del necesario diálogo entre revelación y razón, entre interioridad y exterioridad, es decir, una defensa del valor objetivo de la fe.

En todo ello la tolerancia juega un papel decisivo. No una tolerancia pasiva que nos incita a aprender a aceptar al otro como otro, sino, antes, una tolerancia activa que se incorpora en el sujeto como parte esencial de su configuración, previa a todo posible conflicto con un otro contrapuesto. No hay contraposición, pues ésta, en rigor, sólo se puede producir entre dos sujetos, mas la identidad de éstos no se decide únicamente en el ámbito de la interioridad, sino que lo hace por igual en el de la exterioridad. Y en éste, el encuentro con el otro constituye justamente su posibilidad, con lo que se desdibujan las fronteras.

En esta concepción de la subjetividad, que antepone la tolerancia como configuradora de una identidad que no se puede producir apriorísticamente, la figura del sabio, como educador del género humano, adquiere una especial relevancia. El sabio asume y ejerce, ejemplarmente, una tolerancia activa, porque es sabedor de la posibilidad de armonía: entre la convicción íntima y la acción exterior, o dicho de otra manera, entre la realidad individual del sujeto y el marco colectivo en que ésta está llamada a producirse. El sabio conoce esta armonía y sabe, por ello, estar en la contradicción ${ }^{51}$, sin que esto signifique dejarse hundir en ella o resolverla en falso por medio de una tolerante exclusión de una de las partes. El sabio cree en una armonía posible que supere realmente los falsos dilemas que conducen a la violencia y a la intolerancia. Y así escribe Lessing en El cristianismo de la razón:

Como cada uno de esos seres simples [las criaturas de Dios] tiene algo que no tienen los otros y ninguno de ellos puede tener algo que los otros no tengan, resulta que entre estos seres simples tiene que haber una armonía a partir de la cual hay que explicar todo lo que sucede entre ellos, es decir, en el mundo. ${ }^{52}$

\footnotetext{
50 Lessing (1970-79), vol. 8, pp. 502-503 (énfasis añadido).

51 El propio Lessing, amante de la contradicción y la polémica, cuya filosofía acoge la ambigüedad, sería un ejemplo de sabio (cf. Berghahn 2005, p. 82; Nisbet 2005, p. 146).

$52 \quad$ Lessing (1970-79), vol. 7, p. 280.
} 
La tarea humana es producirse moralmente, y esto lo entiende Lessing como un doble reconocimiento, a través del encuentro con el otro, de las perfecciones que uno tiene en sí y de las imperfecciones a superar, manifestadas en el sujeto como ensimismantes ${ }^{53}$. «Obra de acuerdo con tus perfecciones individuales» es la consigna, derivada de una ley «tomada de [nuestra] propia naturaleza» ${ }^{54}$. Para ello, una tolerancia entendida en sentido activo, vinculada a la tarea de producirse como sujeto, también por venir, constituye una incuestionable alianza.

No sorprende que Hannah Arendt diese a sus "pensamientos en torno a Lessing" el tan revelador título de "Sobre la humanidad en tiempos oscuros". El individuo, concreción de lo humano, lo mismo que el sabio, como su paradigma, deben estar en el mundo, y dejar de hacerlo supone una pérdida del «específico y con frecuencia irreemplazable entremedio que se debería haber formado entre [el] individuo y sus semejantes $\rangle^{55}$. Más allá del ensimismamiento que favorecen ciertas concepciones de la subjetividad de otros autores en la misma órbita de la Ilustración, en Lessing encontramos un humanismo que evita el individualismo de raíz, promoviendo en su lugar la apertura al otro, justamente como parte de una comprometida búsqueda de sí. Y para esto de poco vale una tolerancia que sea, en realidad, un egoísmo enmascarado, propio de quien soberanamente decide tolerar al otro después de haberlo aislado y neutralizado, desde la absoluta soberanía de principios racionales absolutos ${ }^{56}$.

Lessing camina en sentido opuesto a este itinerario de inspiración kantiana, apunta Arendt. Para él, como ya señalábamos líneas arriba, "la verdad" en sí misma poco importa. En palabras de la propia Arendt:

Lessing, no obstante, se recreó precisamente en aquello que de siempre -o al menos desde Parménides y Platón- atormentó a los filósofos: que la verdad, en el momento en que es expresada, es inmediatamente transformada en una opinión entre muchas, es refutada, reformulada, reducida a un objeto de discurso entre otros. La grandeza de Lessing no consiste meramente en una concepción teórica de que no pueda haber una única verdad en el mundo humano, sino en su alegría por que no existe y que, en consecuencia, el interminable discurso entre los hombres no cesará nunca mientras haya hombres. ${ }^{57}$

Una humanista búsqueda del sujeto ligada a un sólido fundamento escéptico sustentan la heterodoxa concepción de la tolerancia de Lessing. De hecho, en su

\footnotetext{
Como también es ensimismante una razón que se repliega ante lo otro de la revelación.

Ibid., p. 281.

Arendt (1983), pp. 4-5.
}

56 También en el ámbito de la razón práctica existe un apriorismo equivalente al que Kant desarrolla en la Crítica de la razón pura. Así encontramos, por ejemplo, la siguiente definción: «Persona es el sujeto, cuyas acciones son imputables. La personalidad moral, por tanto, no es sino la libertad de un ser racional sometido a leyes morales (...) de donde se desprende que una persona no está sometida a otras leyes más que las que se da a sí misma» (Kant 1989, p. 30). La definición obedece al ideal ilustrado de autonomía, tal como se nos presenta en la célebre "Respuesta a la pregunta ‘¿Qué es Ilustración?’”. Y no debemos olvidar que en este texto Kant piensa muy particularmente en una autonomía respecto de la religión (Kant 2004, pp. 85ss), como también desarrollará en otros momentos: «Así pues, la moral por causa de ella misma (tanto objetivamente, por lo que toca al querer, como subjetivamente, por lo que toca al poder) no necesita en modo alguno de la religión, sino que se basta a sí misma en virtud de la razón pura práctica» (Kant 1995, p. 19).

57 Arendt (1983), p. 27. Y así también la parábola de los tres anillos es interpretada por Arendt en los mismos términos: si se supiese cuál es el verdadero anillo se acabarían el discurso, la amistad y la humanidad (vid. ibid., p. 26). Importa la promesa de la verdad que mueve hacia su búsqueda en el diálogo, no tanto la propia verdad como resultado. 
encomio, la propia Arendt hace explícita esta conexión, subrayando justamente esa misma heterodoxia implícita no ya en un beneplácito, sino, más aún, una celebración de la disidencia, de la discordancia, que tiene «muy poco que ver con la tolerancia en el sentido ordinario (de hecho el propio Lessing no era ni mucho menos una persona especialmente tolerante), y tiene mucho que ver con el don de la amistad, con la apertura al mundo, y finalmente con el genuíno amor a la humanidad ${ }^{58}$.

Podemos así concluir afirmando que la contraposición entre una tolerancia pasiva y una activa, que nos permite discriminar la concepción de Lessing de otras de autores del mismo marco de la Ilustración, no obedece meramente a distintos modos de ver el ejercicio de la tolerancia en particular, sino que viene dada por maneras contrapuestas de concebir el sujeto en su relación, no sólo con el otro -lo que se expresa más inmediatamente en una demanda de tolerancia-, sino también con eso otro que la revelación es para la razón. Desde el punto de vista de una subjetividad constituida enteramente sobre principios racionales, ambas otredades son asimiladas por una tolerancia pasiva que funciona, en realidad, como ratificación de esos mismos principios racionales, y por tanto del sujeto por ellos constituido. Lessing, en cambio, nos ofrece una singular alternativa según la cual la tolerancia tiene ante todo un sentido activo, y con éste un lugar anterior: pues el encuentro con el otro -y con lo otro para la razón- deviene ahora configurador de la propia identidad del sujeto, que se forma no tanto ante el otro como ya con el otro y por el otro. Y esta alternativa concepción de la tolerancia, finalmente, no se entiende sin una complementaria concepción de la verdad, que integra la revelación como educadora de una razón llamada a mantenerse permanentemente en su búsqueda.

\section{Referencias bibliográficas}

Andreu, A. (2008): “Introducción”, en G. E. Lessing, Natán el sabio, edición de A. Andreu, Barcelona, Anthropos, pp. xix-lxxxv.

Arendt, H. (1983): Men in Dark Times, Nueva York, Harvest.

Berghahn, K. L. (2005): "Lessing the Critic: Polemics as Enlightenment", en B. Fischer y T. C. Fox (eds.), A Companion to the Works of Gotthold Ephraim Lessing, Rochester, Candem House, pp. 67-87.

Boccaccio, G. (1956): Decameron, Turín, Utet.

Boller, P. F. y George, J. (1989): They Never Said It, Nueva York, Oxford University Press. Camps, V. (1990): Virtudes públicas, Madrid, Espasa-Calpe.

Charles, S. (2011): “Tolerancia activa y pasiva según Voltaire”, en M. J. Villaverde Rico, J. C. Laursen (eds.), Forjadores de la tolerancia, Madrid, Tecnos, pp. 212-223.

Fischer, B. y Fox, T. C. (2005): "Lessing's Life and Work", en B. Fischer y T. C. Fox, op. cit., pp. 13-39.

Forst, R. (2013): Toleration in Conflict. Past and Present, Nueva York, Cambridge University Press.

Gaos, J. (1982): De la filosofia, en Obras completas, vol. 12, México, UAM.

Goetschel, W (2005): "Lessing and the Jews", en B. Fischer y T. C. Fox, op. cit., pp. 185-208. Horton, J. y Mendus, S. (1985): Aspects of Toleration. Philosophical Studies, Londres, Methuen.

58 Ibid., p. 26. 
Hunter, I. (2011): "Libertad religiosa y coacción racional. Thomasius y Locke sobre la tolerancia”, en M. J. Villaverde Rico, J. C. Laursen, op. cit., pp. 116-140.

Kant, I. (1989): La Metafísica de las costumbres, edición de A. Cortina y J. Conill, Madrid, Tecnos.

Kant, I. (1995): La religión dentro de los límites de la mera razón, edición de F. Martínez Marzoa, Madrid, Alianza.

Kant, I. (2004): ¿Qué es Ilustración?, edición de R. R. Aramayo, Madrid, Alianza.

Lessing, G. E. (1970-79): Werke, 8 vols., Munich, Carl Hanser.

Lessing, G. E. (1982): Escritos filosóficos y teológicos, ed. de A. Andreu, Madrid, Editora Nacional.

Levine, A. (2001): Sensual Philosophy. Toleration, Skepticism, and Montaigne's Politics of the Self, Lanham, Lexington Books.

Locke, J. (1991): A Letter Concerning Toleration in Focus, edición de J. Horton y S. Mendus, Londres, Routledge.

Locke, J. (1999): Escritos sobre la tolerancia, edición de L. Prieto y J. Betegón, Madrid, Centro de Estudios Políticos y Constitucionales.

Locke, J. (2005): Segundo tratado sobre el gobierno civil, Buenos Aires, Prometeo.

Marcuse, H. (1965): "Repressive Tolerance", en R. P. Wolff, B. Moore y H. Marcuse, A Critique of Pure Tolerance, Boston, Beacon Press.

Mill, J. S. (2003): On Liberty, en Utilitarianism and On Liberty, edición de M. Warnock, Oxford, Blackwell.

Nicholson, P. P. (1985): “Toleration as a Moral Ideal”, en J. Horton y S. Mendus (eds.), Aspects of Toleration. Philosophical Studies, Londres, Methuen, pp. 158-173.

Nisbet, H. B. (2005): "Lessing and Theology", en B. Fischer y T. C. Fox, op. cit., pp. 133154.

Nonnotte, C.-F. (1773): Dictionnaire philosophique de la religion, s.1.

Rousseau, J.-J. (1964): Du contrat social, en Euvres complètes, vol. 3, París, Gallimard.

Voltaire (1961): Traité sur la tolérance à l'occasion de la mort de Jean Calas, en Mélanges, París, Gallimard.

Zedler, J. H., Ed. (1731-54): Grosses vollständiges Universal-Lexicon aller Wissenschafften und Künste, 68 vols., Leipzig, Zedler. 